
\title{
\& Research Square \\ Variation in the material properties by nickel substitution in copper tellurate
}

Sudarshana Dhanarath Mardolkar ( $\nabla$ sudarshanamar@gmail.com )

Goa University https://orcid.org/0000-0002-0356-3699

\section{A. V. Salker}

Goa University

\section{Research Article}

Keywords: Nickel doped copper tellurate, microstructures, electrical, magnetic, photoluminescence

Posted Date: May 15th, 2020

DOl: https://doi.org/10.21203/rs.3.rs-28567/v1

License: (c) (i) This work is licensed under a Creative Commons Attribution 4.0 International License. Read Full License 


\section{Abstract}

A series of pristine and nickel doped copper tellurates possessing a wide range of applications are studied here. Use of a simple wet chemical route that is co-precipitation method has been employed for the first time, which involves the formation of desired compounds at a relatively lower temperature, thus modifying their properties. All the prepared compounds are characterized and investigated by XRD, TG DTA, XPS, SEM, TEM to examine their phase purity, thermal stability, chemical state, and microstructural properties. The electrical resistivity studies showed an insulator - semiconductor transition behavior. Magnetic studies revealed the paramagnetic nature of the material. Antiferromagnetic to paramagnetic transition was observed at $\mathrm{T} \mathrm{N} \sim 60 \mathrm{~K}$ in case of $\mathrm{Cu} 2.7 \mathrm{Ni} 0.3 \mathrm{TeO} 6$ sample. Thermoelectric studies indicated a change in conduction mechanism with temperature. Dielectric properties with respect to frequency showed an increase in dielectric parameters with increasing dopant content. Photoluminescence property has been studied and found to show emission in the visible region.

\section{Introduction}

A sustainable approach towards the synthesis of any material has become a necessity due to over utilization of natural resources. Efficient use of sources with least or no wastage should serve as a good approach in synthesizing a material. Study of tellurium-containing compounds, especially tellurates show the potential application in low temperature co-fired ceramics (LTCC) technology as they can be prepared and sintered at low temperatures [1,2]. Tellurates show a wide range of applications in the fields of electronic, magnetic, multiferroics, optics, etc. due to their remarkable solid state properties [3-8].

Doping or substitution of any material with another element is known to bring about change in its properties thus changing its applicability. It allows one to tune or advance the skills of a material and in turn provide immense output to the techno world. In the present research, nickel as a dopant is chosen to alter the behavior of pristine composition due to their ability to hold some interesting physical properties. A detailed study on copper tellurate and cobalt doped copper tellurate have been discussed earlier [9] to possess distinct properties.

Nickel being a ferromagnetic element could possibly develop the magnetism in copper tellurate which is found to be paramagnetic at room temperature. Nickel substituted copper tellurate compounds have been structurally studied by B. Wedel et al [10] synthesized via melt-quench technique, wherein they concluded that, nickel doped copper tellurate possesses structure isotype to copper tellurate with octahedral site shared by both copper and nickel. Solid solutions of $(\mathrm{Cu}, \mathrm{Ni})_{3} \mathrm{TeO}_{6}$ synthesized via solidstate route have been studied for their phase transitions and the effect of nickel substitution for their various properties [11-13].

Here, we present a precise study over nickel doped copper tellurate for a variety of properties for future applications via co-precipitation route. The change in properties brought up by simply substituting nickel in copper tellurate will definitely attract many researchers worldwide to explore deeply in the fields of 
material science. The studies of photoluminescence property open new doors of research for these materials.

Preparation of such compounds is mostly through to solid state studies, whereas, here we have made use of a simple wet chemical method that is co-precipitation, which involves very simple methodology of precipitating the ions in an aqueous form, then drying it and finally calcining it at the desired temperature. Such a method involves a lower range of temperature $\left(600-700^{\circ} \mathrm{C}\right)$ than the usual temperature required via solid state synthesis.

\section{Materials And Methods}

\subsection{Sample preparation}

Initially, metal nitrate salts were brought in the solution form. These metal ions were precipitated by means of a suitable base like $\mathrm{NaOH}$. $\mathrm{TeO}_{2}$ was used as a source of Te ions, which was dissolved in $\mathrm{NaOH}$ solution. The hydroxide form of metal ions thus precipitated were filtered, washed with distilled water and dried in air. On complete drying the precipitate, it was ground to a fine size. This precursor was heated at $200^{\circ} \mathrm{C}$ for $3 \mathrm{~h}$ in an oven. It was again ground to homogenize and finally sintered at $400^{\circ} \mathrm{C}$ for $3 \mathrm{~h}$ and $600{ }^{\circ} \mathrm{C}$ for $5 \mathrm{~h}$ continuously in the air to generate Ni-doped copper tellurate. In this manner, $\mathrm{Cu}_{3-\mathrm{x}} \mathrm{Ni}_{\mathrm{x}} \mathrm{TeO}_{6}$ $(x=0.2,0.3,0.4$ and 0.5$)$ compositions were prepared.

\subsection{Characterization}

Thermal analysis of the precursor compound was carried out up to $800^{\circ} \mathrm{C}$ at the heating rate of $10^{\circ} \mathrm{C}$ $\min ^{-1}$ using STA 409 PC Luxx simultaneous TG-DTA analyzer (Netzsch, Germany) to understand the thermal behavior of the precursors and thermal stability of the prepared compounds. X-ray diffraction analysis (XRD) was performed on RigakuUltima IV using Cu Ka radiation $(\lambda=1.5418 \AA$ ) in the $2 \theta$ range $10-80^{\circ}$ which confirmed the phase formation. Morphological and chemical characterization of the prepared samples were carried out using the instrument Zeiss Evo18 Scanning Electron Microscope and energy dispersive spectroscopy (Jeol Japan). Transmission Electron Microscopy (TEM) performed on Philips CM 200 transmission electron microscope to observe the nature of pristine and doped copper tellurate particles. X-ray photoelectron spectra (XPS) obtained using PHI Versa probe II instrument, in order to understand the surface composition and chemical state of the samples. The magnetization of the doped samples at room temperature and lower temperature $(50 \mathrm{~K})$ was checked using Quantum Design VSM Versa Lab free instrument. Electrical resistivity studies were carried out using a two-probe conductivity cell in the air for the heating cycle. Two probe TEP measurements set up was used to measure thermoelectric power property. Dielectric constant and loss tangent were measured with a highfrequency LCR meter (Wayne Kerr 6500P) at room temperature and also at a higher temperature $\left(600^{\circ} \mathrm{C}\right)$ over $1 \mathrm{kHz}-10 \mathrm{MHz}$ frequency range. All the compounds studied for the photoluminescence property 
using the instrument Jobin Yvon Flurolog-3-11 Spectroflurometer with xenon lamp source to measure the excitation-emission spectra.

\section{Results And Discussion}

\subsection{TG-DTA}

Fig. 1 shows TG-DTA analysis on the precursor of $\mathrm{Cu}_{2.7} \mathrm{Ni}_{0.3} \mathrm{TeO}_{6}$ synthesized via co-precipitation. An endotherm in the DTA curve is observed at $\triangle 250^{\circ} \mathrm{C}$ with corresponding weight loss in the TG curve. This is because of the water present in the precursor which is lost on heating. The loss of adsorbed moisture / water takes place first followed by the loss of lattice water. As mentioned before, the copper tellurate structure holds a molecule of water within itself [14]. It can be seen from Fig. 1 that the TG curve reveal two step weight loss process from $30-250^{\circ} \mathrm{C}$ with respective kinks in DTA. Thus, this could be considered for the loss of physisorbed water and structural water. At around $550^{\circ} \mathrm{C}$, DTA shows a sharp exothermic peak indicating conversion of amorphous to crystalline phase with no weight loss further in TG curve.

\subsection{XRD}

X-ray diffraction studies on $\mathrm{Cu}_{3-\mathrm{x}} \mathrm{Ni}_{\mathrm{x}} \mathrm{TeO}_{6}(\mathrm{x}=0,0.2,0.3,0.4$ and 0.5$)$ tellurates are presented in Fig. 2 All the peaks are assigned to the cubic system with space group la3 [15] and reveal the monophasic formation of pristine and doped compounds with all peaks corresponding to the reported data (JCPDS card \# 22-0251).

\section{$3.3 \mathrm{XPS}$}

The XPS spectra for nickel doped copper tellurate compound $\mathrm{Cu}_{2.7} \mathrm{Ni}_{0.3} \mathrm{TeO}_{6}$ is presented in Fig. 3 (a). Fig. 3 (b) shows spectra for $\mathrm{Cu} 2 \mathrm{p}$ with two major peaks i.e. $\mathrm{Cu} 2 \mathrm{p}_{3 / 2}$ and $\mathrm{Cu} 2 \mathrm{p}_{1 / 2}$ at $934.49 \mathrm{eV}$ and 954.41 $\mathrm{eV}$ along with their respective satellites, confirming its existence in 2+ oxidation state [16]. The spectrum for dopant $\mathrm{Ni} 2 \mathrm{p}$ is shown in Fig. 3 (c), which reveals the presence of nickel in 2+ valence, as it displays $\mathrm{Ni}$ $2 p_{3 / 2}$ major peak at $855.3 \mathrm{eV}$ along with its satellite at $861.6 \mathrm{eV}[17,18]$. Te $3 \mathrm{~d}$ spectrum (Fig. $3 \mathrm{~d}$ ) shows two peaks at $576.4 \mathrm{eV}$ and $586.7 \mathrm{eV}$ for $\mathrm{Te} 3 \mathrm{~d}_{5 / 2}$ and $\mathrm{Te} 3 \mathrm{~d}_{3 / 2}$ representing its $\mathrm{Te} \mathrm{C}^{6+}$ form [19]. The fitting spectrum for $01 \mathrm{~s}$ (Fig. 3 e) shows characteristic peaks at $529.7 \mathrm{eV}$ and $532 \mathrm{eV}$ which are attributed to the bonded lattice oxygen and defect oxygen respectively [20].

\subsection{SEM}

Fig. 4 (a) represents SEM images for Ni-doped copper tellurate for $\mathrm{Cu}_{2.7} \mathrm{Ni}_{0.3} \mathrm{TeO}_{6}$ composition. They show cube shaped morphologies with densely packed particles. It is very much clear from the figure that the particles possess well-developed grain boundaries. Particle sizes are found to lie in the micron range. 
EDS data is reported for $\mathrm{Cu}_{2.7} \mathrm{Ni}_{0.3} \mathrm{TeO}_{6}$ and $\mathrm{Cu}_{2.5} \mathrm{Ni}_{0.5} \mathrm{TeO}_{6}$ (Fig. $4 \mathrm{~b}$ and $4 \mathrm{c}$ ). The observed percentage composition values of each element are in good agreement with the values obtained from theoretical calculations.

\subsection{TEM}

The TEM of nickel-doped copper tellurate compounds are presented in Fig. 5 which show agglomerated particles with irregular morphologies. Particle dimensions are found to lie in the micron range. The images represent particles of nickel-doped copper tellurates to decrease, with an increase in nickel dopant concentration. The dense-equiaxial, micro grains are seen to possess well-developed grain boundaries.

\subsection{Electrical resistivity}

Fig. 6 presents a series of resistivity plots for nickel doped copper tellurate compounds carried out in the air from room temperature to $450^{\circ} \mathrm{C}$. There appear two distinct regions; one towards the lower side of temperature which behaves like an insulator and the other semiconductor which lies at a higher temperature. The resistivity of material remains stable up to the certain value of temperature and then increases sharply at high temperature $\left(T_{c}\right)$ (Table 1$)$. It is also noticed here that, in the insulator type region, the value of resistivity is almost same for all the compositions of tellurates. Whereas the semiconductor region show varied resistivity values as they approach higher temperature.

\subsection{Magnetic Study}

$\mathrm{Cu}_{3-\mathrm{x}} \mathrm{Ni}_{\mathrm{x}} \mathrm{TeO}_{6}(\mathrm{x}=0,0.3$ and 0.5$)$ prepared by co-precipitation method were analysed for their magnetic property. Pristine copper tellurate and nickel doped copper tellurate as shown in Fig. 7 ( $a$ and b) were found to exhibit a linear variation of $\mathrm{M}-\mathrm{H}$ curve revealing usual anti-ferromagnetic/paramagnetic spins favorable at low temperature. Saturation magnetization is not observed in the entire range of magnetic field in all compounds. There is an increasing trend in magnetization observed on doping nickel ion in pristine copper tellurate. Since $\mathrm{Ni}$ is a ferromagnetic ion, it is supposed to show increment in magnetization as it does. Analyses carried out at $50 \mathrm{~K}$ comparatively show higher values than the analyses carried out at room temperature. Magnetization with respect to temperature was studied at 500 Oe and the plot represents antiferromagnetic to paramagnetic transition at around $60 \mathrm{~K}$ as shown in Fig. 7c.

\subsection{TEP}

Thermoelectric power measurements were carried out in order to measure the conduction phenomena on the prepared samples, which displayed semiconductor behavior at a higher temperature. Fig. 8 represents the plot of Seebeck coefficient versus temperature from $40-400{ }^{\circ} \mathrm{C}$ for $\mathrm{Cu}_{3-\mathrm{x}} \mathrm{Ni}_{\mathrm{x}} \mathrm{TeO}_{6}(\mathrm{x}=0,0.2,0.3,0.4$ and 0.5 ) compounds in a two probe TEP measurement set up. A sudden change in " $a$ " is observed which immediately drops down to the negative region signifying a conduction mechanism/phase change. 
Similar observations could be drawn from the doped compounds showing p-type to n-type transition [9]. The dropped down values closely resemble the values obtained by DC resistivity measurements (Table 1).

\subsection{Dielectric study}

Trends of dielectric constant and dielectric loss with a log of frequency were observed for nickel doped copper tellurates in Fig. 9. This series of compounds were found to show a rise in their dielectric properties on doping with nickel. Dielectric constant and dielectric loss are high at a lower frequency as at lower energies, the dipoles lie separated, thus producing high permittivity, further loses it, as polarization occurs at the higher side of frequency. The properties are raised considerably on replacing the Cu ion by $\mathrm{Ni}$ in small concentration.

The highest concentration of nickel-doped copper tellurate presents similar patterns for dielectric $\mathrm{v} / \mathrm{s}$ temperature studies as above. An increase in $\dot{\varepsilon}$ and $\tan \delta$ is observed with an increase in temperature because the orientation of dipoles is facilitated at a higher temperature. A drop in $\dot{\varepsilon}$ and $\tan \delta$ is observed with increasing frequency as the dipoles are unable to reciprocate to the change in the AC electric field (Fig. 10).

\subsection{Photoluminescence study}

Fig. 11 shows $\mathrm{PL}$ of a pristine $\mathrm{Cu}_{3} \mathrm{TeO}_{6}$ along with Ni-doped copper tellurate compound at room temperature. Excitation in UV region of $260 \mathrm{~nm}$ produces an emission in the visible region at $\sim 485 \mathrm{~nm}$ with blue-cyan color radiation. The PL spectrum of undoped copper tellurate is dominated by a strong/intense band. The luminescence intensity was observed to drop down drastically on nickel doping. As seen in Fig. 11. with an increase in dopant concentration, there is a decrease in the PL intensity, suggesting that the degree of recombination of electron-hole pair shrink as the dopant develop an impurity level close to valence band thereby preventing diffusion of electron and hole causing lowering of $\mathrm{PL}$ intensity, thus leading to reduced band gap energy $[21,22]$. Doped ones show reduced particle sizes than the un-doped.

\section{Conclusion}

Nickel doped copper tellurate compounds were successfully synthesized via co-precipitation technique. The precursor and the final samples were investigated for TG-DTA and IR studies to differentiate between them. The monophasic formation of all the doped compounds has been confirmed using XRD. The morphological investigations using SEM and TEM helped in understanding the particle shape and size. Full scan spectra along with high-resolution individual spectra of the doped compound revealed the existence of expected ions in their requisite chemical states. A distinct transition from insulator to semiconductor was observed from the electrical resistivity study. A transition was also noticed from thermoelectric power study, indicating a mechanism similar to that in electrical resistivity. Magnetization versus temperature study showed antiferromagnetic to paramagnetic spins at $\mathrm{T}_{\mathrm{N}}$. The magnetic property 
with respect to the magnetic field showed an increase in magnetism with an increase in the dopant concentration. The dielectric parameters were determined to examine dielectric behavior. Photoluminescence study over tellurates provided blue cyan emission with excitation in UV region. Replacement of $\mathrm{Cu}$ with Ni cause the significant tuning of the PL strength hence, finding its application in fields of optoelectronics. Consequently, all the compounds prepared and studied for various properties are expected to serve for futuristic applications in a wide range of fields.

\section{Declarations}

Acknowledgement: Authors are thankful to UGC-New Delhi, for financial Assistance.

\section{References}

[1]M. Udovic, M. Valant, D. Suvorov, Characterization of the $\mathrm{Bi}_{2} \mathrm{O}_{3}-\mathrm{TeO}_{2}$ system with respect to oxygen partial pressure, Key Eng. Mater. 2002, 206-213: 1409-1412.

[2]M. Udovic, M. Valant, D. Suvorov, Dielectric characterisation of ceramics from the $\mathrm{TiO}_{2}-\mathrm{TeO}_{2}$ system, J. Eur. Ceram. Soc. 2001, 21:1735-1738.

[3]X. Su, A. Wu, P.M. Vilarinho, $\mathrm{Al}_{2} \mathrm{TeO}_{6}$ : Mechanism of phase formation and dielectric properties, $\mathrm{Scr}$. Mater. 2012, 67: 927-930.

[4]M. Herak, Cubic magnetic anisotropy of the antiferromagnetically ordered $\mathrm{Cu}_{3} \mathrm{TeO}_{6}$, Solid State Commun. 2011, 151:1588-1592.

[5]Z. He, M. Itoh, Magnetic behaviors of $\mathrm{Cu}_{3} \mathrm{TeO}_{6}$ with multiple spin lattices, J. Magn. Magn. Mater. 2014, 354: $146-150$.

[6]I. Živković, K. Prša, O. Zaharko, H. Berger, $\mathrm{Ni}_{3} \mathrm{TeO}_{6}-\mathrm{A}$ collinear antiferromagnet with ferromagnetic honeycomb planes, J. Phys. Condens. Matter. 2010, 22: 056002.

[7]J. Zupan, D. Kolar, V. Urbanc, Magnetic properties of $\mathrm{Ni}_{3} \mathrm{TeO}_{6}$, Mat. Res. Bull. 1971, 6: 1353-1359.

[8]P. Pal, S. R. Mohapatra, S. D. Kaushik, A. K. Singh, Structural, dielectric and magnetic studies of $\mathrm{Fe}_{2} \mathrm{TeO}_{6}$ and $\mathrm{Fe}_{2} \mathrm{Te}_{0.96} \mathrm{Nb}_{0.04} \mathrm{O}_{6}$ ceramics, AIP Conf. Proc. 2016, 1832: 140026.

[9]S. D. Mardolkar, A. V. Salker, Efficiently synthesized $\mathrm{Co}$ doped $\mathrm{Cu}_{3} \mathrm{TeO}_{6}$ accounted for its anomalous behaviour in electronic properties, New J. Chem. 2017, 41:13974-13982.

[10]B. Wedel, I. Kimio, K. Sugiyama, Crystal structure of dicopper nickel hexaoxotellurate, $\mathrm{Cu}_{2} \mathrm{NiTeO}_{6}$, Zeitschrift Fur Krist. - New Cryst. Struct. 2001, 216: 345-346. 
[11]G. M. Kaleva, E. D. Politova, S. A. Ivanov, A. V. Mosunov, S. Y. Stefanovich, N. V. Sadovskaya, R. Mathieu, P. Nordblad, Phase transitions of $\left(\mathrm{Cu}, \mathrm{Ni}_{3} \mathrm{TeO}_{6}\right.$ solid solutions, Inorg. Mater. 2011, 47: 11321140.

[12]R. L. O. R. Cunha, I. E. Gouvea, L. Juliano, A glimpse on biological activities of tellurium compounds, An. Acad. Bras. Cienc. 2009, 81:393-407.

[13]A. Fleming, On the specific antibacterial properties of penicillin and potassium tellurate, J. Pathol. Bacteriol. 1932, 35: 831-842.

[14]A. C. Roberts, T. S. Ercit, R. S. Williams, M. C. Jensen, California, and from the Centennial Eureka mine, Juab County, Utah I, Mineral. Mag. 1994, 58: 417-424.

[15]X. Zhu, Z. Wang, X. Su, P.M. Vilarinho, New $\mathrm{Cu}_{3} \mathrm{TeO}_{6}$ Ceramics: Phase Formation and Dielectric Properties, ACS Appl. Mater. Interfaces. 2014, 6: 11326-11332.

[16]O. Akhavan, R. Azimirad, S. Safa, E. Hasani, $\mathrm{CuO} / \mathrm{Cu}(\mathrm{OH})_{2}$ hierarchical nanostructures as bactericidal photocatalysts, J. Mater. Chem. 2011, 21: 9634-9640.

[17]N. Weidler, J. Schuch, F. Knaus, P. Stenner, S. Hoch, A. Maljusch, R. Scha, B. Kaiser, W. Jaegermann, Xray Photoelectron Spectroscopic Investigation of Plasma- Enhanced Chemical Vapor Deposited NiO, J. Phys. Chem. C. 2017, 121: 6455-6463.

[18]R. S. Ganesh, E. Durgadevi, M. Navaneethan, V. L. Patil, S. Ponnusamy, C. Muthamizhchelvan, S. Kawasaki, P. S. Patil, Y. Hayakawa, Controlled synthesis of Ni-doped ZnO hexagonal microdiscs and their gas sensing properties at low temperature Controlled synthesis of Ni-doped ZnO hexagonal microdiscs and their gas sensing properties at low temperature, Chem. Phys. Lett. 2017, 689: 92-99.

[19]W. E. Sartz, K. J. Wynne, D. M. Hercules, X-ray photoelectron spectroscopic investigation of Group VI-A elements, Anal. Chem. 1971, 43: 1884-1887.

[20]S. R. Naik, A. V. Salker, S. M. Yusuf, S. S. Meena, Influence of $\mathrm{Co}^{2+}$ distribution and spin-orbit coupling on the resultant magnetic properties of spinel cobalt ferrite nanocrystals, J. Alloys Compd. 2013, 566: 54-61.

[21]D. Beydoun, R. Amal, G. Low, S. Mcevoy, Role of nanoparticles in photocatalysis, J. Nanoparticle Res. 1999, 1: 439-458.

[22]B. Khoshnevisan, M. Bagher, $\mathrm{Fe}^{3+}$-Doped Anatase $\mathrm{TiO}_{2}$ Study Prepared by New Sol-Gel Precursors, Chinese Phys. Lett. 2018, 35: 27501.

\section{Figures}




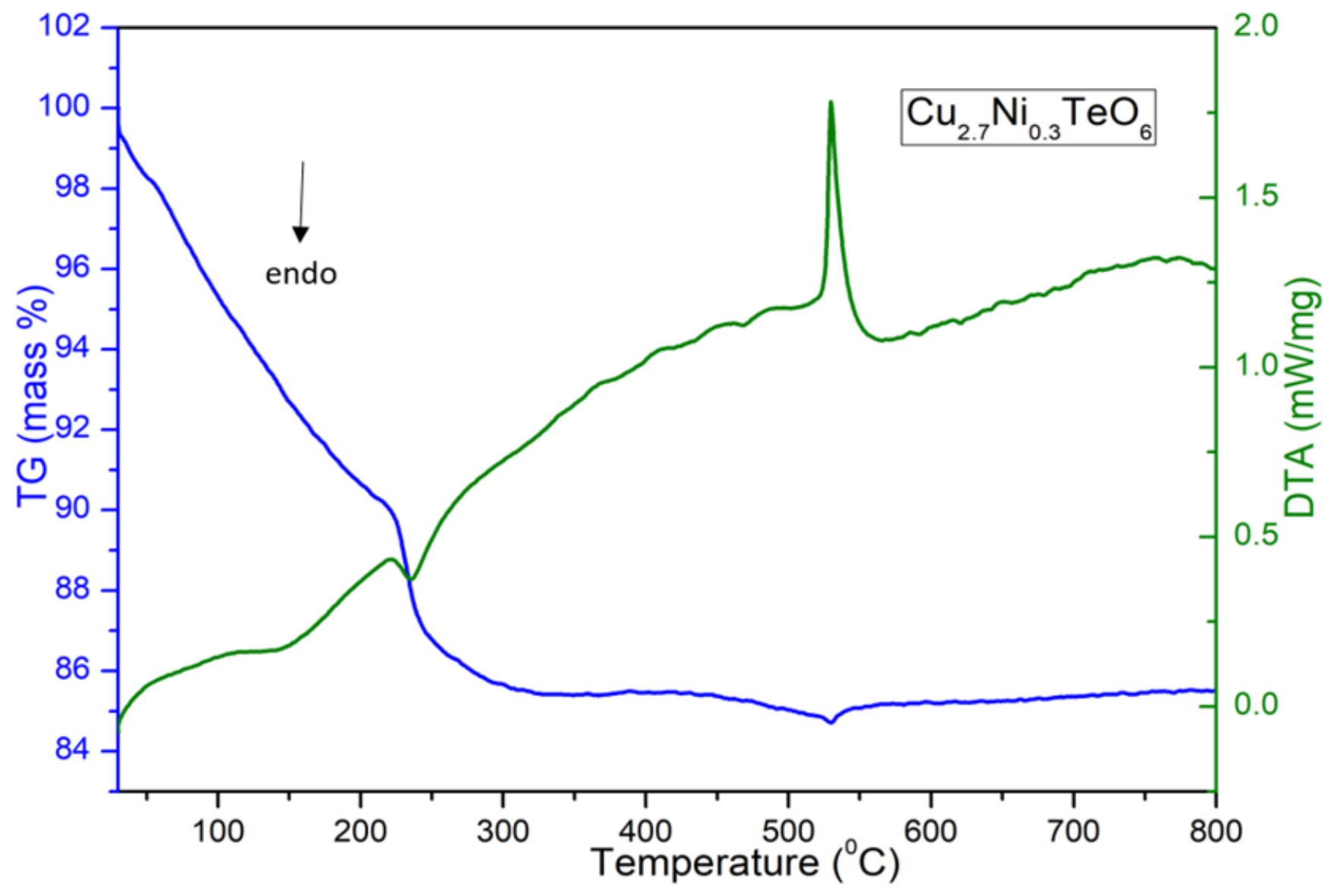

Figure 1

TG-DTA curves of Cu2.7Ni0.3TeO6 precursor 


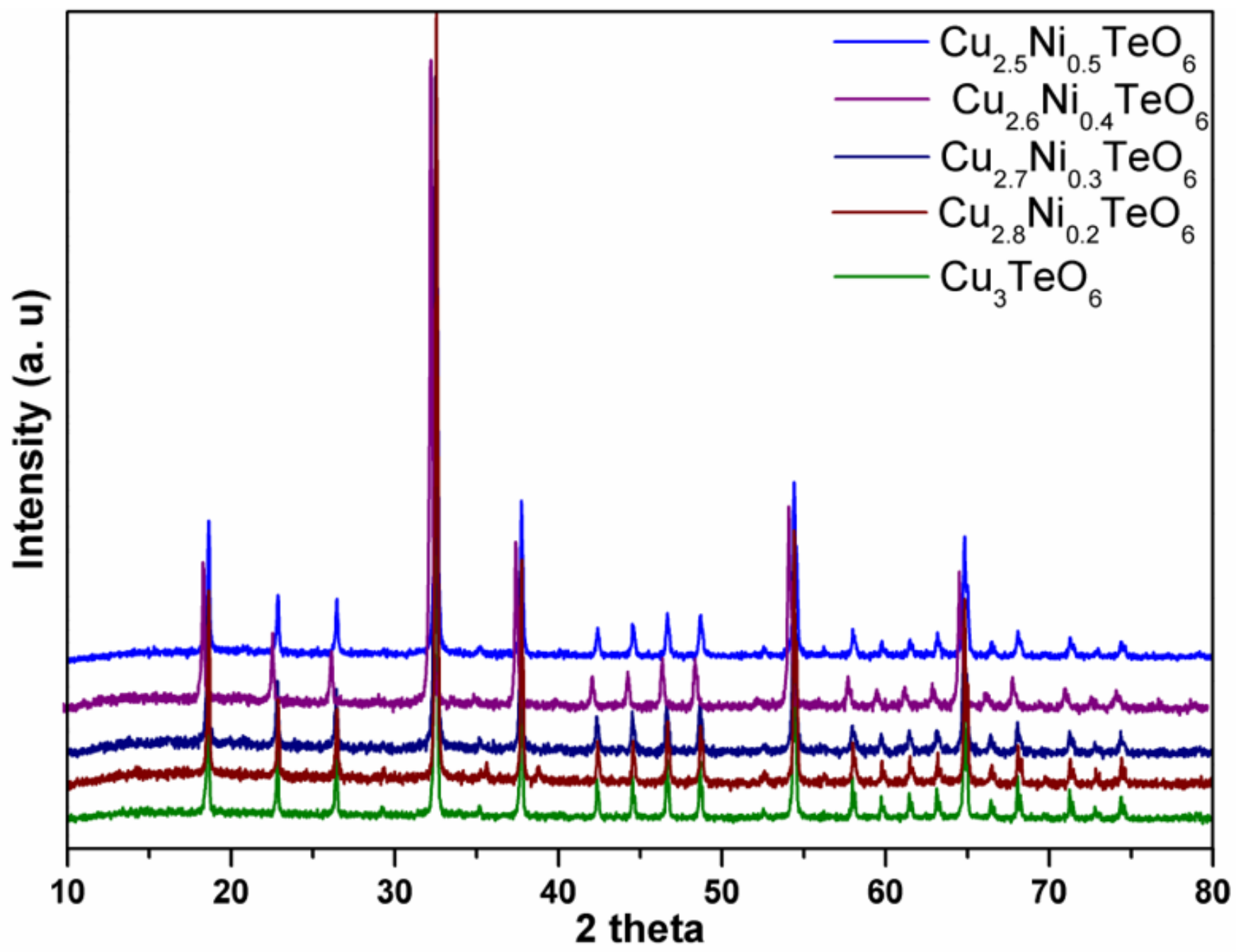

Figure 2

XRD pattern representing $\mathrm{Cu} 3 \mathrm{TeO} 6$ and $\mathrm{Ni}$-doped $\mathrm{Cu} 3 \mathrm{TeO} 6$ in one phase 

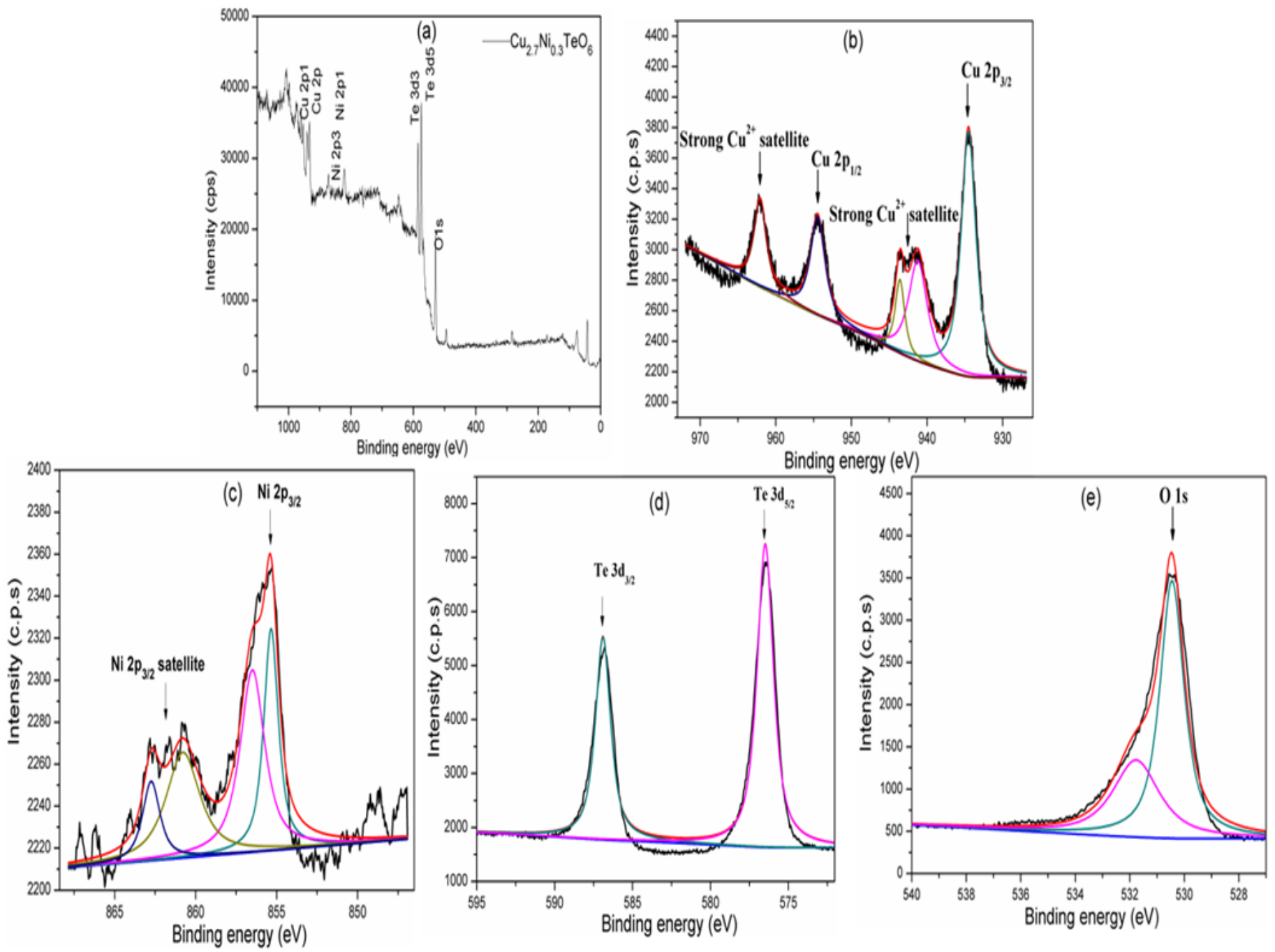

Figure 3

XPS scan for Cu2.7Ni0.3TeO6 showing (a) full scan (b) Cu 2p (c) Ni 2p (d) Te 3d (e) 0 1s peaks 


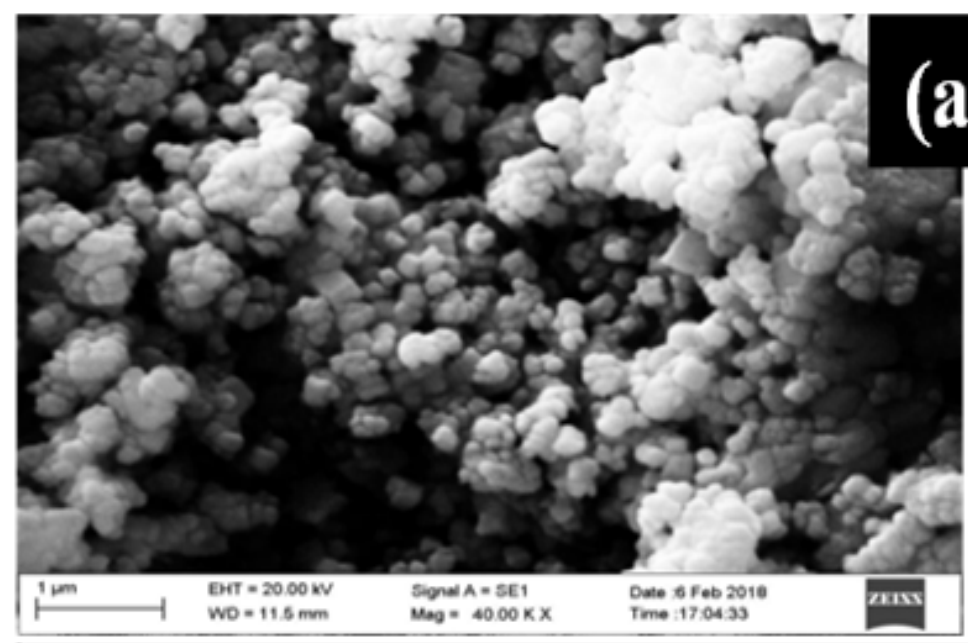

(a)
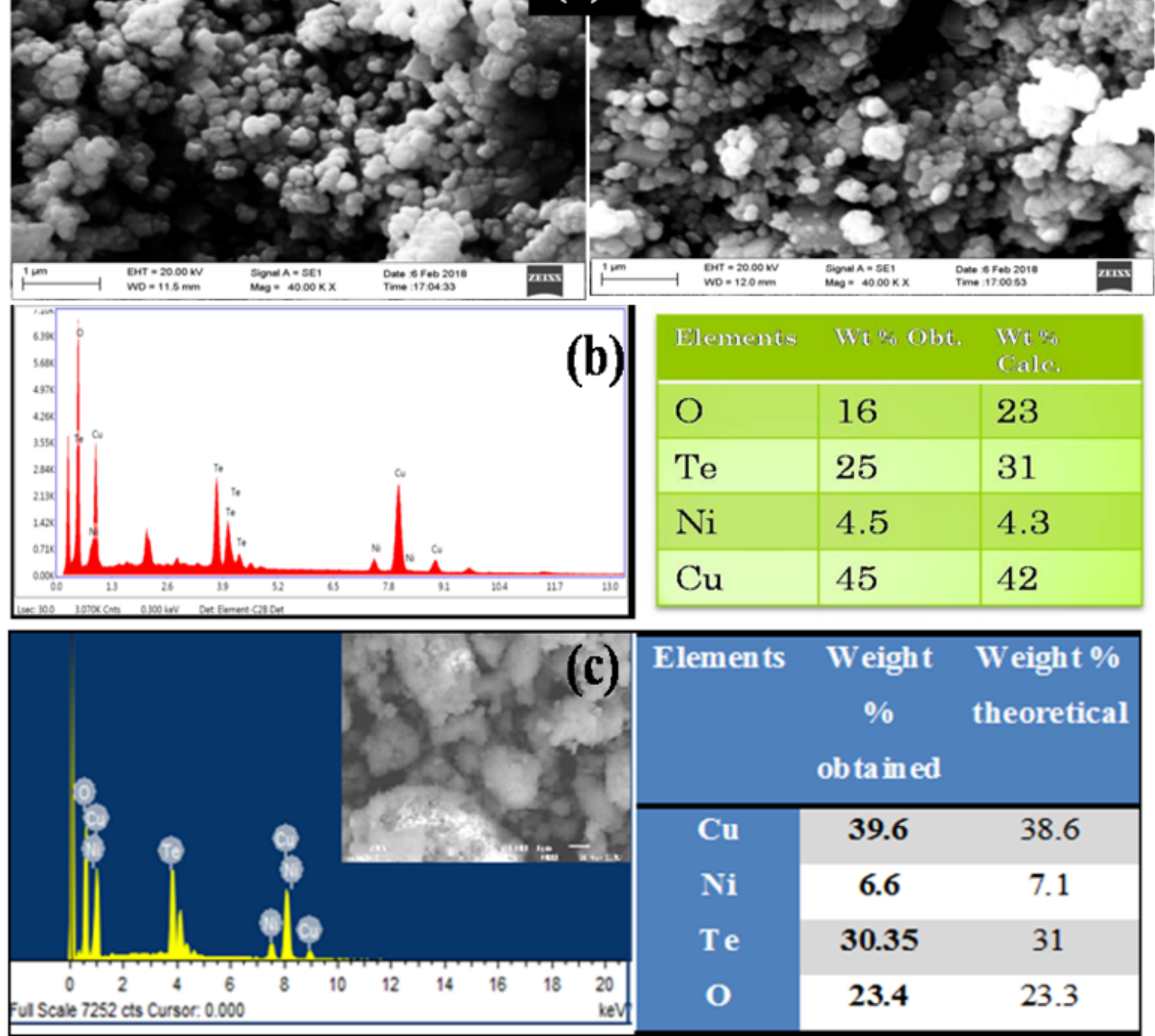

Elements Weight Weight $\%$

$\%$

theoretical

obtained

\begin{tabular}{|c|cc|}
\hline $\mathrm{Cu}$ & $\mathbf{3 9 . 6}$ & 38.6 \\
$\mathrm{Ni}$ & $\mathbf{6 . 6}$ & 7.1 \\
$\mathrm{Te}$ & $\mathbf{3 0 . 3 5}$ & 31 \\
$\mathrm{O}$ & $\mathbf{2 3 . 4}$ & 23.3 \\
\hline
\end{tabular}

Figure 4

SEM images of (a) Cu2.7Ni0.3Te06, (b) EDS of Cu2.7Co0.3TeO6 and (c) Cu2.5Co0.5TeO6 respectively. 


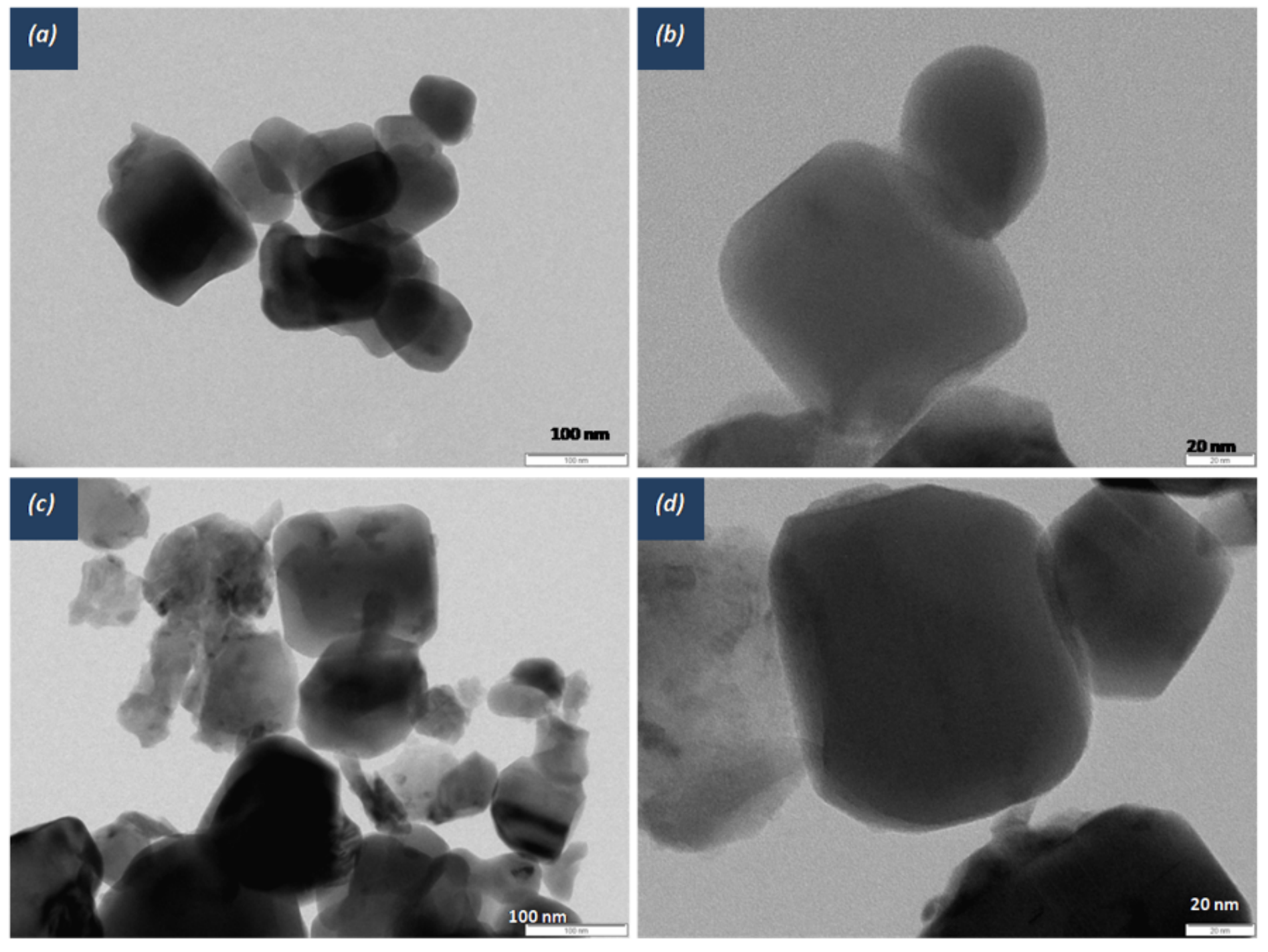

Figure 5

TEM images of Cu2.5Ni0.5TeO6 (a, b) and Cu2.7Ni0.3TeO6 (c, d). 


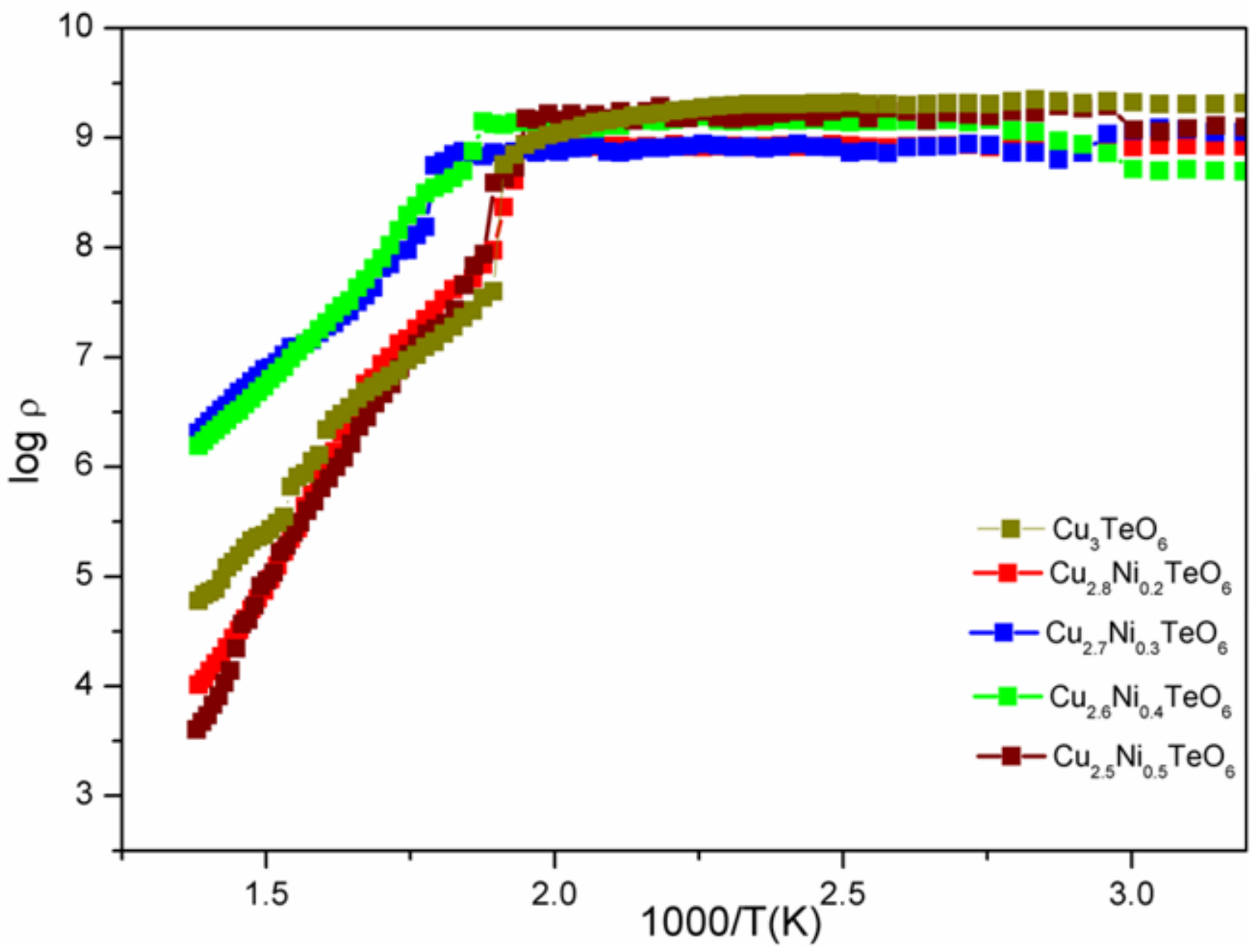

Figure 6

Plot of log resistivity v/s 1000/T for Cu3-xNixTeO6 $(x=0,0.2,0.3,0.4$ and 0.5$)$ in air for heating cycle. 

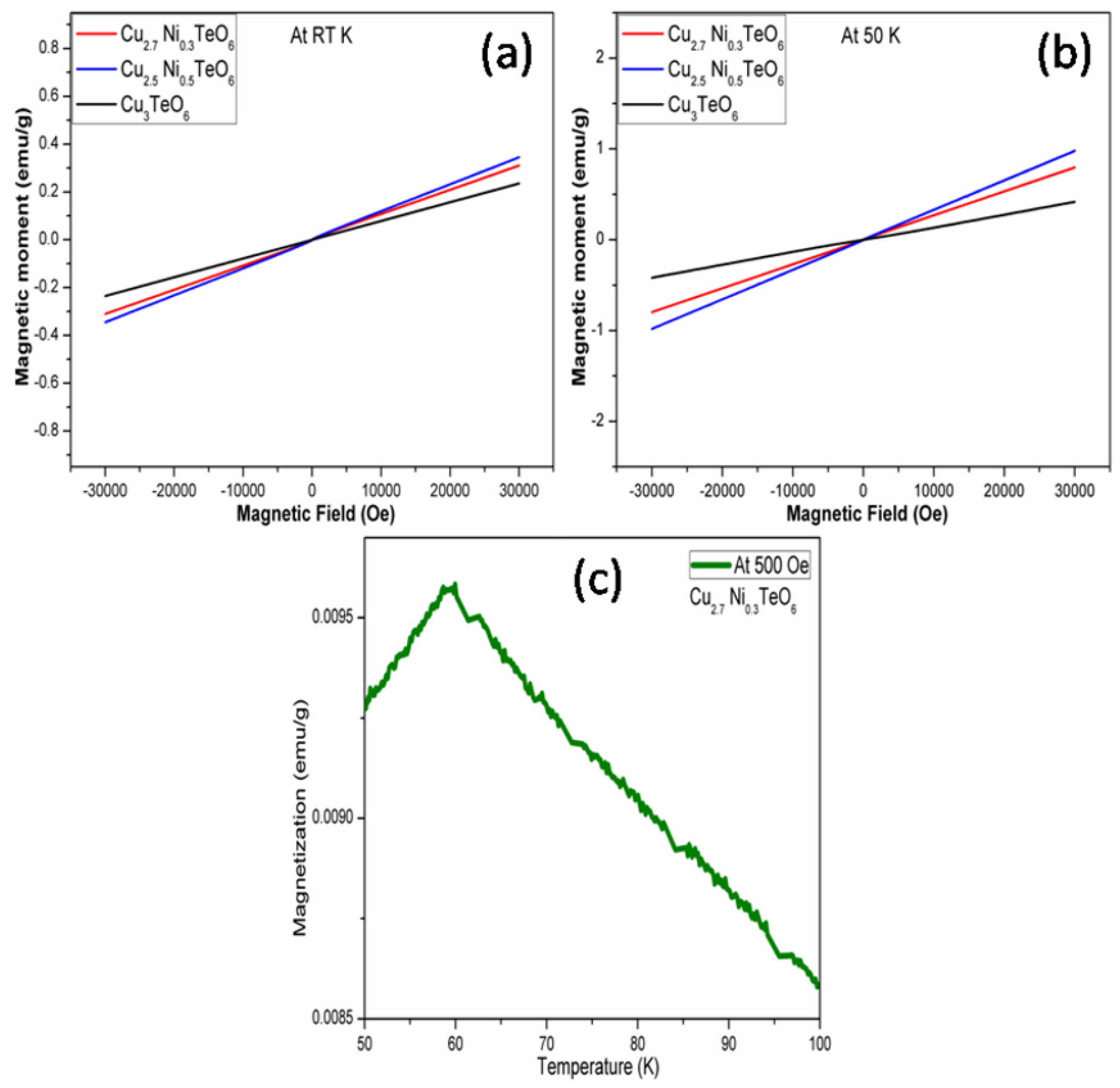

Figure 7

Shows magnetization v/s applied magnetic field plots for Ni-doped copper tellurate compounds at room temperature (a) and at $50 \mathrm{~K}$ (b). Antiferromagnetic to paramagnetic transition observed at TN (c). 


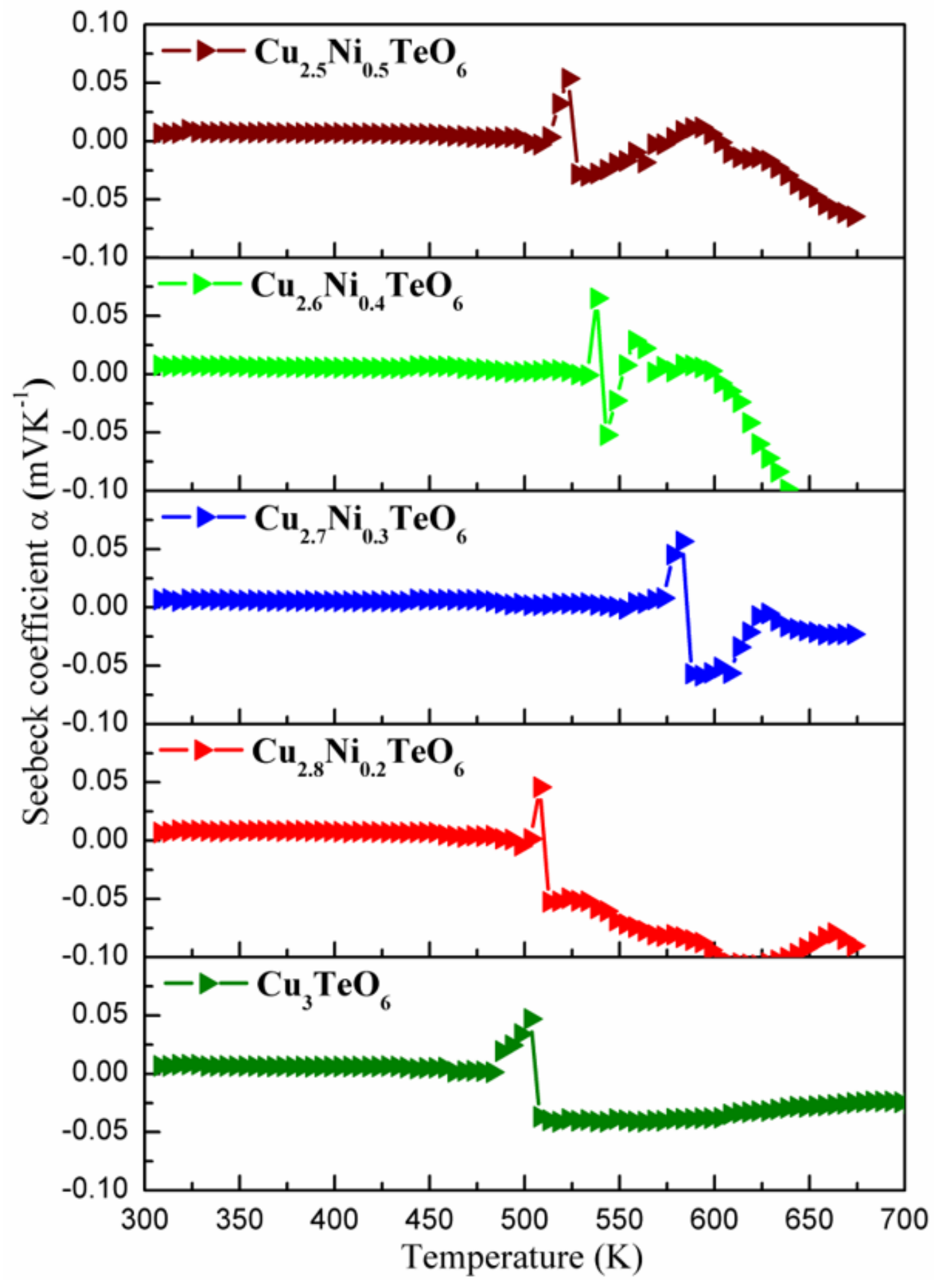

Figure 8

Plot of Seebeck coefficient v/s temperature for Cu3-xNixTeO6 ( $x=0,0.2,0.3,0.4$ and 0.5) 


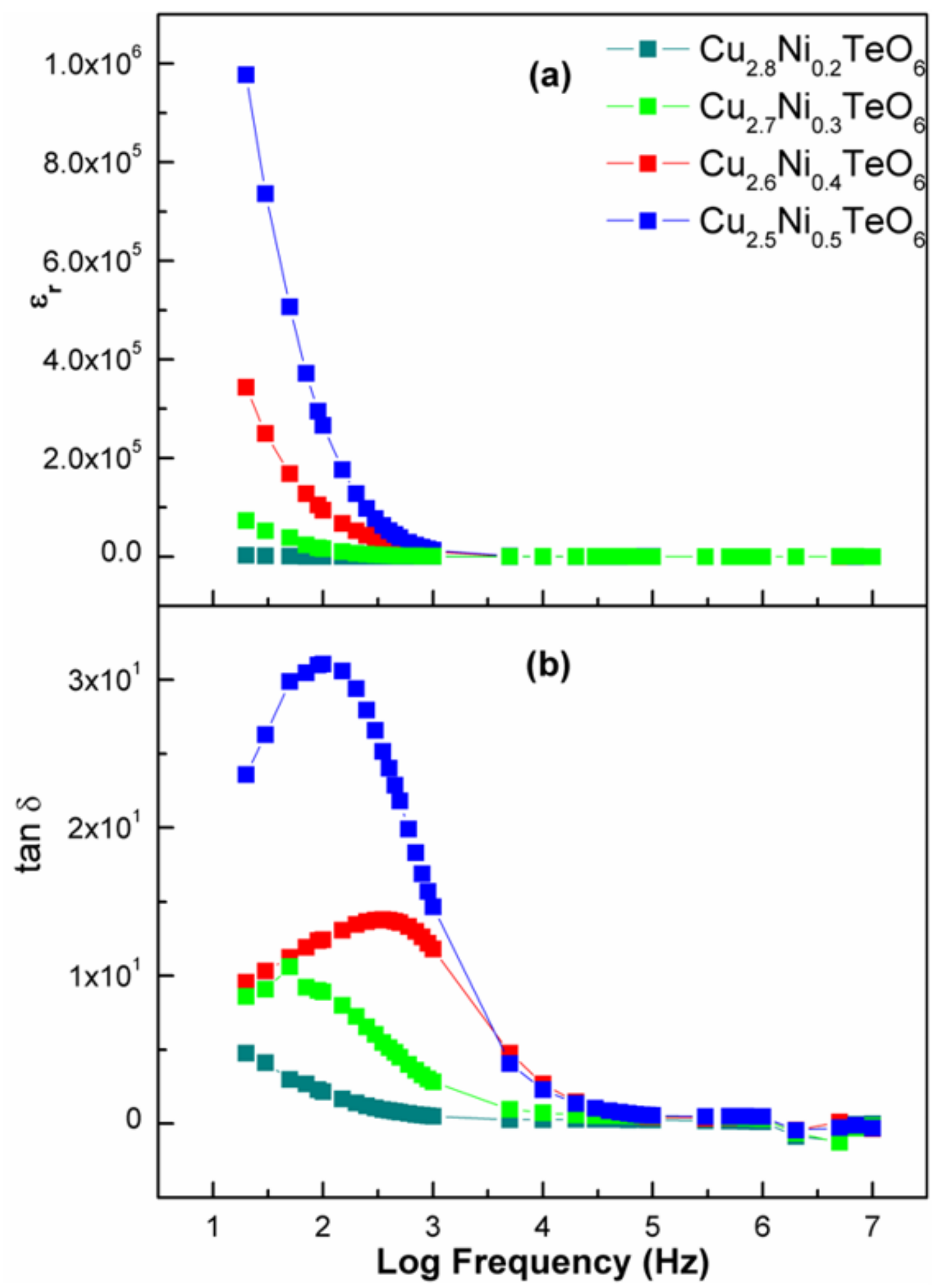

Figure 9

The frequency-dependent (a) relative permittivity and (b) dielectric loss for Ni-doped Cu3TeO6 at room temperature. 


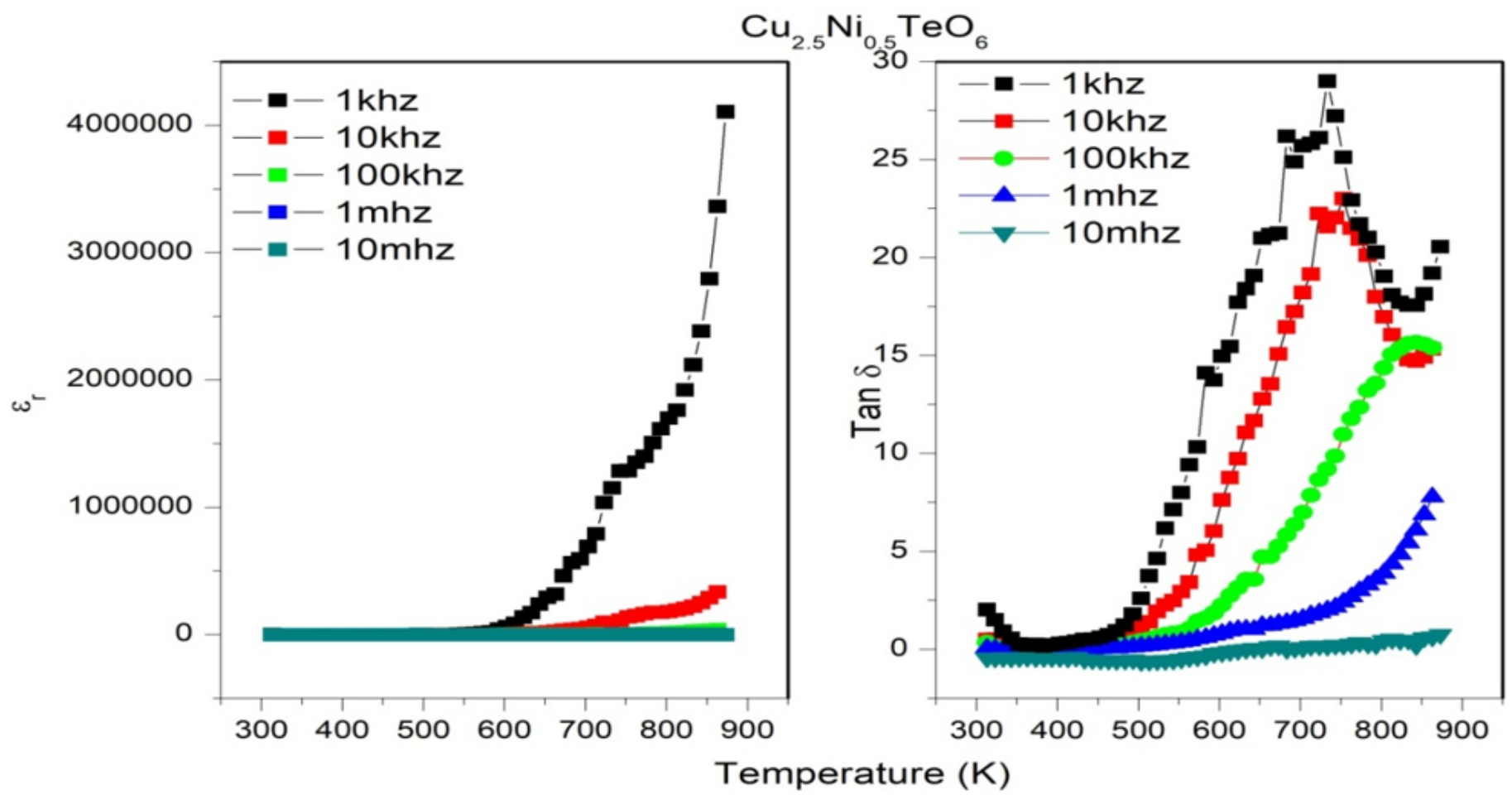

Figure 10

The temperature-dependent relative permittivity and dielectric loss for $\mathrm{Cu} 2.5 \mathrm{Ni0} .5 \mathrm{TeO} 6$ at variable frequencies. 


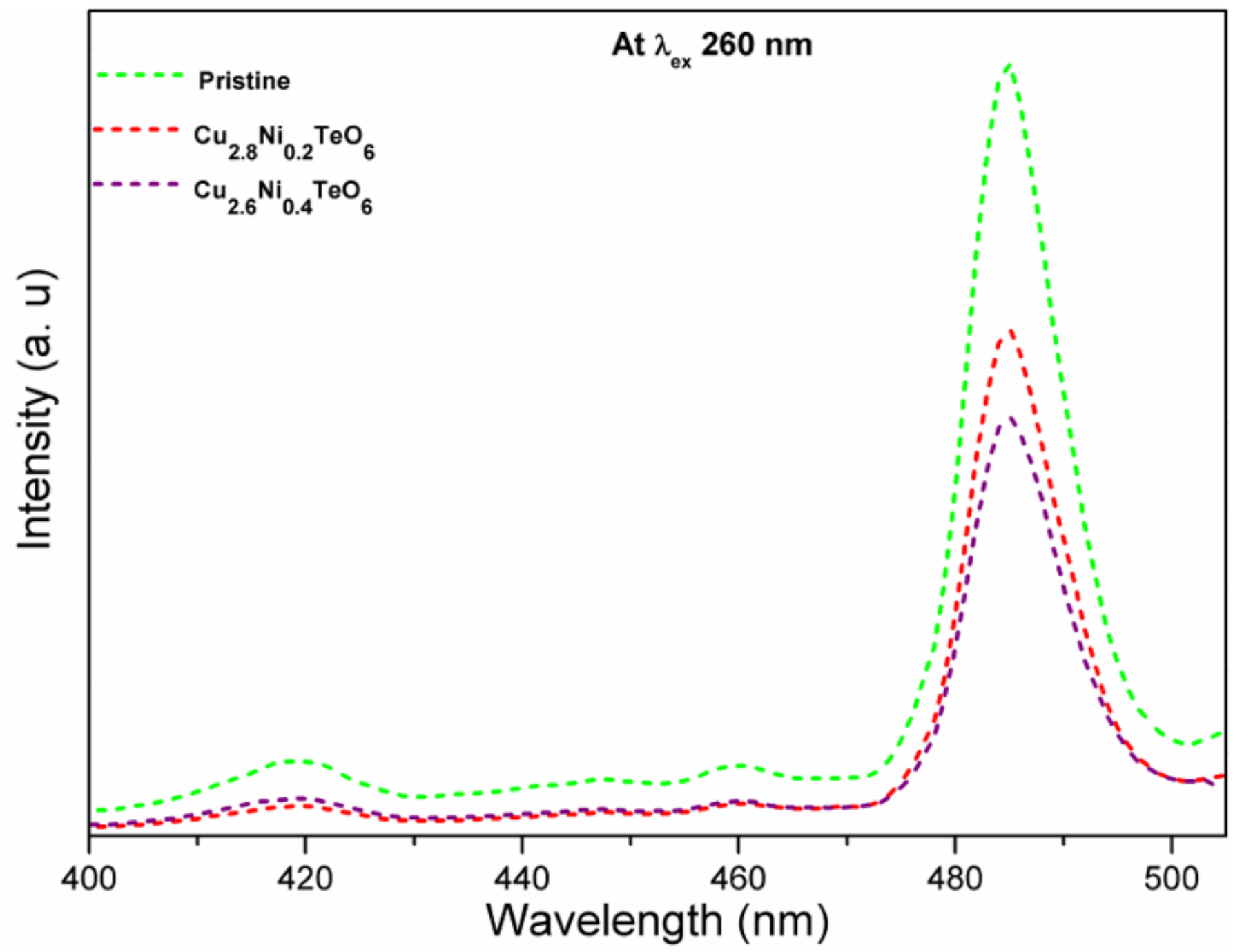

Figure 11

Photoluminescence spectrum of Ni-doped copper tellurate. 